ISSN 2238-118X

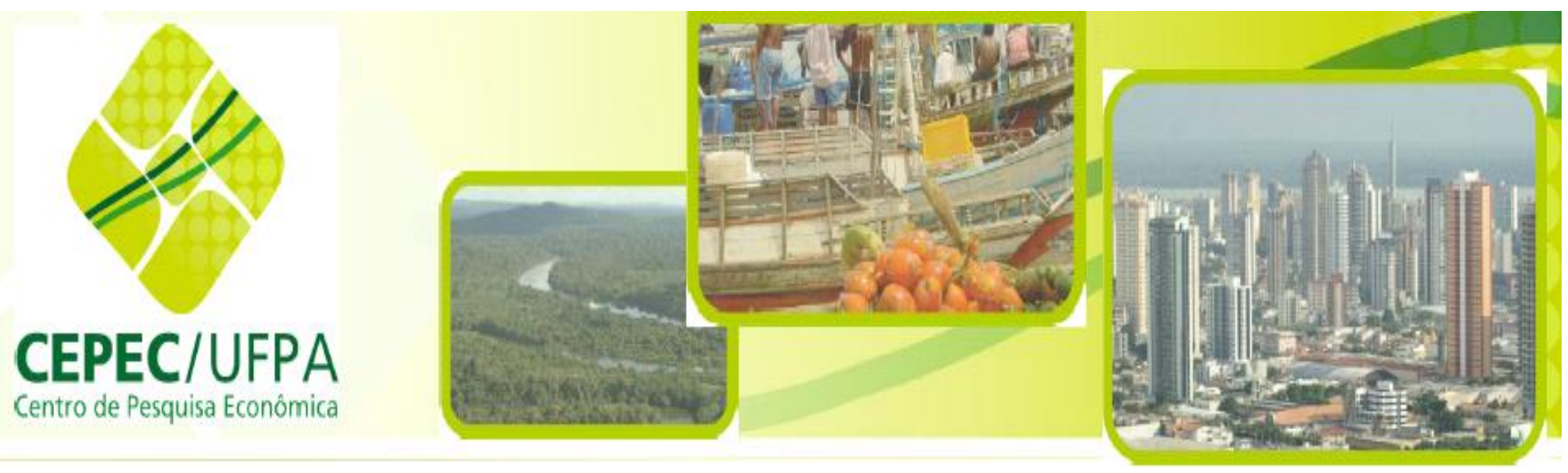

CADERNOS CEPEC

V. 5 N.06 Junho de 2016

DEPENDÊNCIA E DESENVOLVIMENTO SOCIOESPACIAL NA AMAZÔNIA: O CASO DO MANGANÊS NO AMAPÁ

Rosana Amorim

Indira Cavalcante da Rocha Marques

Centro de Pesquisas Econômicas da Amazônia

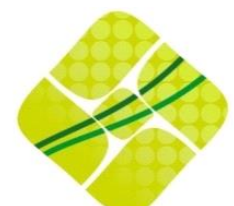

CEPEC/UFPA

Centro de Pesquisa Econômica 


\section{CADERNOS CEPEC}

Publicação do Programa de Pós-graduação em Economia da Universidade Federal do Pará.

Periodicidade Mensal - Volume 5 - N06 - Junho de 2016

Reitor em Exercício: Horácio Shneider

Pró-Reitor de Pesquisa e Pós Graduação em Exercício: Iracilda Sampaio

Instituto de Ciências Sociais Aplicadas

Diretor: Carlos Alberto Batista Maciel

Vice Diretor: Manoel Raimundo Santana Farias

Coordenador do Mestrado e Doutorado em Economia: Ricardo Bruno Nascimento

Editores

José Raimundo Barreto Trindade - Principal

Sérgio Luis Rivero

Conselho Editorial Provisório

$\begin{array}{ll}\text { Armando Souza } & \text { Francisco Costa } \\ \text { Marcelo Diniz } & \text { José Trindade } \\ \text { Ricardo Bruno } & \text { Danilo Fernandes }\end{array}$

Gilberto Marques

Sérgio Rivero

Gisalda Filgueiras

Márcia Jucá Diniz

Comentários e Submissão de artigos devem ser encaminhados ao

Centro de Pesquisas Econômicas da Amazônia, através do e-mail: irtrindade@uol.com.br

Página na Internet: http://www.ppgeconomia.ufpa.br/ 
Cadernos CEPEC

Missão e Política Editorial

Os Cadernos CEPEC constituem periódico mensal vinculado ao Programa de Pósgraduação em Economia do Instituto de Ciências Sociais Aplicadas (ICSA) da Universidade Federal do Pará (UFPA). Sua missão precípua constitui no estabelecimento de um canal de debate e divulgação de pesquisas originais na grande área das Ciências Sociais Aplicadas, apoiada tanto nos Grupos de Pesquisa estabelecidos no PPGE, quanto em pesquisadores vinculados a organismos nacionais e internacionais. A missão dos Cadernos CEPEC se articula com a solidificação e desenvolvimento do Programa de Pós-graduação em Economia (PPGE), estabelecido no ICSA.

A linha editorial dos Cadernos CEPEC recepciona textos de diferentes matizes teóricas das ciências econômicas e sociais, que busquem tratar, preferencialmente, das interrelações entre as sociedades e economias amazônicas com a brasileira e mundial, seja se utilizando de instrumentais históricos, sociológicos, estatísticos ou econométricos. A linha editorial privilegia artigos que tratem de Desenvolvimento social, econômico e ambiental, preferencialmente focados no mosaico que constitui as diferentes "Amazônias", aceitando, porém, contribuições que, sob enfoque inovador, problematize e seja propositivo acerca do desenvolvimento brasileiro e, ou mesmo, mundial e suas implicações.

Nosso enfoque central, portanto, refere-se ao tratamento multidisciplinar dos temas referentes ao Desenvolvimento das sociedades Amazônicas, considerando que não há uma restrição dessa temática geral, na medida em que diversos temas conexos se integram. Vale observar que a Amazônia Legal Brasileira ocupa aproximadamente 5,2 milhões de $\mathrm{Km} 2$, o que corresponde a aproximadamente $60 \%$ do território brasileiro. Por outro lado, somente a Amazônia brasileira detém, segundo o último censo, uma população de aproximadamente 23 milhões de brasileiros e constitui frente importante da expansão da acumulação capitalista não somente no Brasil, como em outros seis países da América do Sul (Colômbia, Peru, Bolívia, Guiana, Suriname, Venezuela), o que a torna uma questão central para o debate da integração sul-americana.

Instruções para submissão de trabalhos

Os artigos em conformidade a linha editorial terão que ser submetidos aos editorialistas, em Word, com no máximo 25 laudas de extensão (incluindo notas de referência, bibliografia e anexos). Margens superior e inferior de 3,5 e direita e esquerda de 2,5. A citação de autores deverá seguir o padrão seguinte: (Autor, data, página), caso haja mais de um artigo do mesmo autor no mesmo ano deve-se usar letras minúsculas ao lado da data para fazer a diferenciação, exemplo: (Rivero, 2011, p. 65 ou Rivero, 2011a, p. 65). Os autores devem fornecer currículo resumido. O artigo deverá vir obrigatoriamente acompanhado de Resumo de até no máximo 25 linhas e o respectivo Abstract, palavraschaves e Classificação JEL (Journal of Economic Literature). 


\title{
Dependência e desenvolvimento socioespacial na Amazônia: o caso do manganês no Amapá ${ }^{1}$
}

Rosana Amorim ${ }^{2}$

Indira Cavalcante da Rocha Marques ${ }^{3}$

\section{Resumo}

Usando a teoria da dependência como subsídio, o artigo analisa a experiência da exploração do manganês do Amapá pela grande empresa mineradora. O objetivo é ter este estudo como referência para a investigação dos processos recentes de extração mineral na Amazônia brasileira.

Palavras-chave: mineração, dependência, desenvolvimento sócio-espacial, Amazônia.

\begin{abstract}
Using the theory of dependency with subsidy, the article analyzes the experience of exploration the Amapá manganese by large mining company. The objective is to have this study as a reference for the investigation of recent processes of mineral extraction in the Brazilian Amazon.
\end{abstract}

Keywords: mining, dependency, socio-spatial development, Amazon.

\footnotetext{
${ }^{1}$ Trabalho desenvolvido com o apoio do Programa PIBIC/UFPA.

2 Graduando do curso de Geografia da Universidade Federal do Pará. Bolsista PIBIC/CNPq. E-mail: rosana.amorimc@hotmail.com.

3 Doutora, professora da Faculdade e do Programa de Pós-Graduação em Geografia da Universidade Federal do Pará. E-mail: indiramarquesgeo@gmail.com.
} 


\section{SUMÁRIO}

1. INTRODUÇÃO

6

2. IMPERIALISMO: APROPRIAÇÃO DE RIQUEZA AO NÍVEL MUNDIAL 9

3. A TEORIA DA DEPENDÊNCIA

4. EXTRAÇÃO DO MANGANÊS DO AMAPÁ PELA GRANDE EMPRESA MINERADORA.

5. A PERMANÊNCIA DA ECONOMIA PRIMÁRIO-EXPORTADORA

6. CONSIDERAÇÕES FINAIS

27

REFERÊNCIAS BIBLIOGRÁFICAS 28 


\section{INTRODUÇÃO}

A grande produção mineral na Amazônia brasileira tem se intensificado nas primeiras décadas do século atual. Novos municípios têm abrigado novos empreendimentos, cujo capital vem de diversos países. A pesquisa conduzida pela professora Indira Rocha Marques (PPGEO/UFPA) aborda este processo, cuja privatização da Companhia Vale do Rio Doce em 1997 é um marco. O ritmo da extração nos municípios mineradores foi acelerado. Resultado: o Pará exporta anualmente aproximadamente 120 milhões de toneladas de ferro e em 2017 deve superar 200 milhões.

Estes empreendimentos dinamizam a economia e sociedade local nos municípios que os abrigam, mas também sofrem outras consequências. Entre as quais, a enorme migração populacional que pressiona da expansão da demanda dos serviços públicos, normalmente acima da capacidade de resposta das administrações municipais. A pergunta que nos colocamos é: esta localização contribui efetivamente para o desenvolvimento socioeconômico regional? Em que medida? Contribui para o desenvolvimento do Brasil ou reforça ainda mais o quadro de expansão de uma economia (particularmente sua balança comercial) sustentada em produtos básicos (com pouca incorporação tecnológica e industrialização)? Isso estimula o desenvolvimentismo ou reforça a dependência (e suas contradições) da região e da nação? Diante do exposto temos a pesquisa tem como objetivo básico analisar o planejamento, implantação e expansão da grande produção energético-mineral na Amazônia Legal brasileira, buscando cruzar o volume de investimentos previstos, a capacidade produtiva dos empreendimentos, a destinação da produção e a demanda por serviços públicos (e expansão demográfica) nos municípios que recebem os empreendimentos. A ideia é refletir sobre como se apresenta o processo de desenvolvimento socieconômico local a partir da ocorrência destes investimentos.

Para subsidiar as reflexões sobre as questões levantadas, recorremos à teoria da dependência, destacadamente sua vertente de origem marxista. Esta elaboração analisa as relações entre nações, em particular entre países industrializados e países subdesenvolvidos. Em suas reflexões, os autores de referência, como Ruy Mauro Marini, Theotônio dos Santos, Vânia Bambirra e André Gunder Frank, entre outros, constatam interdependências entre estes grupos de países, onde o primeiro se apropria de parte da riqueza produzida no segundo grupo de nações. 
A experiência da extração de manganês do amapá é uma referência para analisar a grande produção energético-mineral na Amazônia brasileira. Descoberto em 1945, nos anos seguintes foram feitas as negociações para a exploração do minério e em seguida a montagem da infraestrutura de produção.

Em 1957 foi iniciado a exportação. O contrato de extração, firmado entre o governo brasileiro e a mineradora Icomi, a qual se associou a multinacional Bethlehem Steel, definia 50 anos de exploração. Na segunda metade dos anos 1970 o minério de alto ter já havia sido esgotado e a empresa passava a trabalhar com minérios de menor granulação, menor teor e, por isso, menor valor. Em 1997 a mineradora encerrou formalmente suas atividades no Amapá, tendo explorado mais que o dobro do minério estimado no contrato.

Ficou um rastro de degradação ambiental e social. Serra do Navio, até então uma cidade modelo, transformou-se numa cidade abandonada e sem conservação.

No início do século XXI novas mineradoras se instalaram no Amapá, mas sem a montagem da mesma infraestrutura produtivo-social que foi feita pela Icomi. Como resultado, houve dinamização econômica, mas com muita contradição social-ambiental.

Para estudar a grande produção energético-mineral na Amazônia nas últimas décadas devemos analisar seus dados de produção, mas antes de tudo com a preocupação de olhar os indicadores de desenvolvimento social. Sem o melhoramento destes, esta produção não impulsionará processos sólidos de desenvolvimento, mas o seu inverso.

O presente artigo parte de uma sistematização da teoria da dependência no diálogo com outras vertentes, como é o caso da teoria sobre o imperialismo, e analisa especificamente o caso do manganês no Amapá.

Por quê estudar o manganês do Amapá tendo a teoria da dependência (e mesmo a elaboração sobre imperialismo) como referência? Porque nos levantamos a questão: o atual processo da grande mineração da região tem conduzido a mesma para processos que aumentam sua autonomia, e, como parte disso, ao desenvolvimento socioespacial? Se não é assim, está em curso um movimento inverso: permanência e/ou intensificação das contradições sociais.

O caso do manganês no Amapá é uma experiência de ciclo completo da mineração: descoberta da mina, estabelecimento das condições institucionais, financeiras e infraestruturais necessárias à extração mineral; a produção em si; 
esgotamento da mina; e o desmonte do empreendimento. Analisar esta experiência, nos perguntamos: o que ficou?

A elaboração clássica sobre dependência e imperialismo pode dialogar com interpretações mais recentes, as quais citamos Jaime de Osório, Carlos Martins e David Harvey. No atual momento da pesquisa, estes autores ainda não estão de todo sistematizados. Por isso, quando forem citados, o serão apenas de modo superficial.

Assim, este artigo representa um primeiro momento das investigações da pesquisa conduzida pela professora Indira Marques, cujas etapas seguintes ainda estão em realização.

A pesquisa mantém o objetivo de construir a cartografia da grande mineração na Amazônia. Mas, para tal, faz-se necessário a reunião de um conjunto de informações que estão sendo levantadas.

Destaca-se que não se pretende tão somente reunir dados, mas problematiza-los. Por isso, a necessidade de dialogar com alguns campos teóricos, dos quais a teoria da dependência é um deles. A análise do caso do manganês do Amapá nestes termos se apresenta como um ensaio necessário aos investimentos de maior fôlego da pesquisa.

Por fim, não adotamos a teoria da dependência como verdade absoluta ou camisa de força, mas sentimos a necessidade de revisitar algumas concepções clássicas sobre o pensamento social latino-americano, entre outros. Buscamos estabelecer um diálogo entre este campo e a geografia contemporânea. A partir da síntese da teoria da dependência, queremos colocara a lente da geografia para constatarmos o que esta teoria ainda pode contribuir para o esclarecimento dos fenômenos atuais.

Neste momento da pesquisa, o que temos de mais sólido é a sistematização da teoria da dependência clássica. ${ }^{4}$ Por isso, ela tem mais destaque nesse artigo. Falta sistematizar elaborações recentes, pois ela tem despertado novos estudos e adeptos. Depois disso, será incorporada a contribuição da geografia.

\footnotetext{
${ }^{4}$ Sistematização que é bem mais extensa do que aqui expomos.
} 


\section{IMPERIALISMO: APROPRIAÇÃO DE RIQUEZA AO NÍVEL MUNDIAL}

Ao se consolidar como modo de produção, o capitalismo presencia a fase concorrencial, onde a economia era marcada por um grande número de concorrentes disputando o mercado entre si. Mas a própria disputa entre os capitalistas individuais faz com que alguns se sobreponham aos demais, reduzindo o número de participantes. Esse processo quando se generaliza no decorrer da segunda metade do século XIX conduz a uma nova configuração geopolítica e econômica. Em geral, ela foi denominada de imperialismo.

A definição e caracterização do que seja imperialismo nunca foi consensual. $\mathrm{Na}$ virada do século XX para o atual, muitos autores passaram a negá-lo, Hardt e Negri (2001), por exemplo, ou problematiza-lo no sentido de encontrar as especificidades que agora se apresentavam. Partindo da perspectiva histórico-geográfica David Harvey (2004) se propõe a interpretar o capitalismo global e o papel cumprido pelo "novo imperialismo". Em alguns casos, a problematização conduziu a novas abordagens. Foi o caso de Arrighi e Silver (2001) e Wallerstein (1995 e 2004), para citarmos apenas dois - cuja preocupação mais destacada era a compreensão das mudanças no sistema mundial, em particular da relação de poder entre os Estados-nação, que para os primeiros significava a mudança de hegemonia mundial e para o segundo a decadência do próprio sistema (interestatal) de relação entre as nações. Alguns, como Petras (2002) se empenharam em mostrar que esta definição permanecia atual.

Para o escopo deste artigo não aprofundaremos esta discussão, ainda que a consideremos importante. Em todo caso, resgataremos brevemente duas concepções clássicas: imperialismo e dependência. A segunda será abordada na próxima seção. Para a primeira, ainda que reconhecendo as contribuições de Karl Kautsky, Rosa Luxemburgo, R. Hilferding e Hobson, nos concentraremos em Lênin. Essa opção decorre do fato de que a pesquisa em andamento, e que dá origem ao presente artigo, busca se apropriar dos autores clássicos e dialogar com elaborações mais recentes, de modo a se perguntar se o atual momento de produção de riqueza e configuração espacial da Amazônia brasileira, conduz a um processo de maior autonomia (e conjuntamente ao desenvolvimento socioespacial) ou ao se inverso. Mas algumas etapas da pesquisa e mesmo da sistematização teórico-analítica ainda estão por ser realizadas.

Para Lênin (1987) o imperialismo seria um estágio superior do capitalismo. Num contexto de passagem do capitalismo concorrencial para o capitalismo monopolista, o fenômeno do imperialismo se configuraria quando o capitalismo atingisse um 
determinado grau de desenvolvimento ditado pelo aparecimento de novos agentes e transformações no sistema econômico, de produção e político mundial.

Uma das características mais acentuadas do capitalismo processa-se a partir do alto grau de desenvolvimento da indústria e da concentração da produção em empresas de grande porte, num processo de velocidade frenética. Diante dessa característica, quando se chega a um grau determinado de desenvolvimento juntamente com a concentração da produção, se tem condições que irão culminar na configuração de monopólios. Assim, tem-se um cenário no qual poucas empresas de grande porte são detentoras do controle do mercado devido os altos números de produção e da mão de obra, apontando para a influência da concentração da produção no surgimento de monopólios.

No início do século XX, os cartéis (acordo entre empresas para estabelecer um preço único de um produto no mercado) conseguiram se estabelecer, tendo grande importância no âmbito econômico. Nesse mesmo período, segundo Lênin, o capitalismo transforma-se em imperialismo. A produção configura-se social, mas a apropriação continua a ser privada. Os meios sociais de produção continuam a ser propriedade privada de um número reduzido de indivíduos. A livre concorrência existente na fase anterior (capitalismo concorrencial) já não mais ocorre, ou melhor, não acontece de forma igual, pois o que predomina são os monopólios, cartéis, trustes, detentores do grande capital e por consequência controladores do mercado, constituindo um palco onde as pequenas e médias empresas não têm vez.

Nesse novo estágio, os bancos sobem de posto deixando de serem meros intermediários, passando a ter papel mais relevante no sistema econômico, transformam-se em grandes monopolistas. Segundo Lênin, em qualquer país capitalista, os bancos intensificam e podem, em muitos casos, acelerar o processo de concentração de capital e de formação dos monopólios.

O velho capitalismo que tinha como principais características a livre concorrência e a exportação de mercadorias cede lugar para o novo capitalismo de então, onde há predominância dos monopólios e exportação de capital. Assim, tem-se a passagem do controle do capital (em seu sentido amplo) para o controle do capital financeiro. A concentração da produção, os monopólios, a união dos bancos com a indústria, foram condicionantes para o surgimento do capital financeiro. O capital financeiro segundo Lênin, é o capital bancário de alguns grandes bancos monopolistas 
fundido com o capital das associações monopolistas de industriais, ou seja, é uma nova forma de capital, superior, que passa a controlar a um só tempo a indústria e o banco.

Essa nova fase do capitalismo marcada pela presença dos monopólios, controle do capital financeiro juntamente com uma oligarquia financeira e a exportação de capitais, fez com que se estabelecesse uma divisão econômica mundial de acordo com o interesse desse capital entre seus detentores. Os monopólios e suas derivações são os grandes detentores de poder, controlando e compartilhando o mercado entre si. Isso ocorre devido à grande expressividade do capital financeiro tanto nas relações econômicas nacionais como nas de âmbito internacional. Segundo Lênin, esse capital tem a capacidade de subordinar até os Estados que possuem independência política plena, sendo mais lucrativo e favorável para o capital financeiro à subordinação na qual ocorra perda da independência política dos países e povos submetidos. Assim, o imperialismo também se configura em uma busca por: novas "colônias", territórios visando tanto a expansão econômica como a territorial; domínio das fontes de matériasprimas; e mercado consumidor para os países imperialistas. Em síntese, persegue-se o controle do sistema por essas grandes potências capitalistas, tornando os países subordinados dependentes. Segundo Lenin:

O imperialismo é, pois, o capitalismo na fase de desenvolvimento em que ganhou corpo a dominação dos monopólios e do capital financeiro, adquiriu marcada importância a exportação de capitais, começou a partilha do mundo pelos trustes internacionais e terminou a partilha de toda terra entre os países capitalistas mais importantes (LÊNIN, 2011, p. 228).

No decorrer do século XX, muitas mudanças ocorreram - partes delas analisadas por Eric Hobsbawn (2000). Colônias se tornaram países formalmente independentes, a circulação de mercadorias e capitais se intensificou muito (conduzindo ao que ficou conhecido como globalização), ao capital financeiro foram incorporadas outras características (originando, inclusive, o que alguns analistas nominam como financeirização), instituições multilaterais foram criadas (ONU, Banco Mundial, OMC, FMI, OTAN, entre outras) e surgiram as empresas transnacionais.

Esse conjunto de mudanças e outras mais significaria que o imperialismo seria um conceito ultrapassado, que o mundo se encontra num novo momento onde esta análise não cabe mais? Este é um debate polêmico e não nos propomos aqui aprofundálo - demandaria tempo, espaço e investimento que não nos cabe neste momento e local. Queremos apenas destacar que em muitos aspectos a produção e a decisão política no mundo permanecem concentradas em poucos. 
As grandes decisões políticas mundiais restringem-se a um limitado grupo de países, que em muitos aspectos seus governos se submetem a interesses econômicos e geopolíticos das grandes corporações transnacionais. ${ }^{5}$ Para ficarmos em apenas três casos específicos. Os fluxos de capital, tal qual comprovou Chesnay (1996), se concentram no que ele denominou de tríade: EUA-Europa-Japão (China). Grandes corporações financeiras controlam estes fluxos e podem, inclusive, desestabilizar determinados países e até mesmo a economia mundial. Também a produção mineral é concentrada em poucas empresas. Petróleo, ferro e alumínio são exemplos mais explícitos desta dominância. Ainda que sejam produtos extraídos em inúmeras partes do planeta, a produção de cada um destes minérios está nas mãos de não mais que uma dezena de corporações. O comércio mundial de grãos é dominado por até cinco empresas transnacionais apenas, com destaque para Bunge, Cargill, LDC e ADM.

\section{A TEORIA DA DEPENDÊNCIA}

No contexto do pós-Primeira e Segunda Guerra Mundial, crise de 1929, somado o aumento do protecionismo e nacionalismo, reestabelecia-se a integração da economia mundial juntamente com uma série de mudanças de escala global no cenário político, econômico e social.

A América Latina estava passando por um novo modelo de desenvolvimento socioeconômico. A Teoria da Dependência emerge nos anos 1960 com o objetivo de analisar a permanência da dependência mesmo em países que se industrializavam.

Esse novo processo de desenvolvimento estava ligado ao desenvolvimento industrial, com a instalação das indústrias nos países dependentes nas décadas de 1930 e 1940, que serviram também para a dinâmica de expansão do capital internacional. A partir disso, verificou-se que era necessário repensar o subdesenvolvimento já que a realidade era contrária à teoria de que o subdesenvolvimento existiria por conta da falta de desenvolvimento. Assim, começou-se a entender esses dois fenômenos/processos como produtos do histórico do desenvolvimento do capitalismo, como sistema mundial que produzia simultaneamente os mesmos.

A Teoria da Dependência, segundo Santos (2015), representou um esforço crítico para entender os limites de um processo de desenvolvimento iniciado num

\footnotetext{
${ }^{5}$ Que ainda que se movam na escala mundial e transcendam as fronteiras nacionais, utilizam seus países de origem para pressionar outras nações a aceitarem os interesses econômicos destas empresas.
} 
período histórico em que a economia mundial se estabelecera segundo a hegemonia de grandes grupos econômicos e forças imperialistas dotadas de grande poder, mesmo quando uma parte delas entrava em crise e abria oportunidade para o processo de descolonização. Segundo esta interpretação, o desenvolvimento dependente associado ao capital internacional tinha três características: era dependente, concentrador e excludente. Estes elementos foram acentuados na década de 1980 com a globalização e nos anos 1990 com o consenso de Washington.

As ideias centrais da escola da dependência eram, segundo Blomstrom e Hettne (economistas e estudiosos da teoria), a de que o subdesenvolvimento estava ligado de maneira direta com a expansão dos países industrializados; que o desenvolvimento e o subdesenvolvimento são aspectos diferentes do mesmo processo universal; que o subdesenvolvimento não pode ser considerado como primeira condição para um processo evolucionista e; que a dependência, não é só um fenômeno externo, mas se manifesta também sob diferentes formas na estrutura interna (social, ideológica, política).

Nas décadas de 1970 e 1980 houve uma enorme difusão da teoria juntamente com críticas. Algumas obras buscavam apresentar a Teoria da Dependência como uma escola de pensamento nova, propondo um paradigma científico alternativo à principal corrente do pensamento social ocidental. Outras interpretações, ao contrário, enfatizavam a questão de que a noção de dependência era uma desculpa para explicar o fracasso econômico dos países subdesenvolvidos. Também foram elaborados trabalhos que procuraram aplicar o conceito de dependência à realidade de determinado local.

A América Latina foi o palco no qual essa teoria mais aflorou e avançou. Essa região, desde os primórdios da colonização europeia, era considerada como armazém de recursos naturais apostos para satisfazer as necessidades das economias centrais. Teria, então, a função de ser exportadora de matéria-prima no sistema econômico mundial. Assim como outras regiões de economia dependente do capital internacional, teve seu processo "desenvolvimento" associado ao da industrialização. Para muitos, a industrialização seria uma pré-condição para se alcançar o desenvolvimento. Contudo, diferente do que se pregava, a expansão industrial da América Latina não fez com que seus países chegassem ao status de industriais desenvolvidos, pelo contrário, aumentou a distância em relação aos países centrais, ficando as indústrias obsoletas e poluentes nos países de desenvolvimento médio (SANTOS, 2015). 
A Comissão Econômica para a América Latina (CEPAL), criada como parte da ONU no final dos anos 1940, assumiu a função de auxiliar no desenvolvimento da região latino-americana, preservando as estruturas de poder existentes. Realizava estudos que focavam na busca por políticas capazes de dar suporte ao processo de industrialização, visando à superação de obstáculos referentes ao desenvolvimento. Particularmente na década de 1950, desempenhou papel de suma importância no que diz respeito ao desenvolvimento de uma linha de raciocínio que serviu como alicerce à análise econômica, empírica e também de apoio institucional à busca de bases autônomas de desenvolvimento. Essas bases eram definidas por meio da crença de que a industrialização seria indispensável ao processo de desenvolvimento, pois era aglutinadora e articuladora do mesmo, do progresso, da modernidade, da civilização política e da democracia política. Segundo lideranças mais "modernas" de países subdesenvolvidos, o atraso era consequência de uma especialização da economia, voltada para exportação de produtos primários. Essa linha de raciocínio, e particularmente da Teoria da Dependência, estes países eram atrasados não por conta da ausência de uma revolução burguesa, mas pela não industrialização (CEPAL, por exemplo) ou pela configuração de uma nova dependência mesmo nos países que se industrializavam (Teoria da Dependência). (SANTOS, 2015; GOLDENSTEIN, 1994).

Com a ideia de que o atraso da região era devido ao foco da economia estar direcionado às exportações primárias, a saída se deu pelo processo de substituições de importações. Esse processo, que foi uma das características da industrialização na América Latina, fez com que o crescimento industrial ficasse extremamente dependente das divisas de exportação e também culminou num bloqueio estrutural ao desenvolvimento econômico da região, o qual a CEPAL interviu através de estratégias econômicas e políticas para tentar superar essa situação.

O capital internacional, na realidade, não favorecia o processo de industrialização e sim apoiava o setor e a oligarquia exportadora, assim, o domínio do capital internacional produzia um processo de expropriação das riquezas existentes, em vez de ser um fornecedor de capital e colaborador do desenvolvimento econômico da região.

Diante desse cenário, havia a necessidade de reorientar o investimento internacional, onde novamente a CEPAL teve papel importante, colocando o capital internacional como elemento fundamental de auxilio ao desenvolvimento econômico e industrial dos países da região, agora sendo necessário à industrialização. A CEPAL 
nesse contexto apontava para a perda dos termos de troca relacionados à exportação de produtos primários; hegemonia do setor exportador como obstáculo a industrialização. Contudo, era necessário retirar excedentes desse setor para a indústria, o que exigia mecanismos de intervenção direta através do Estado, por exemplo, a inflação.

Com o avanço do setor industrial havia também a necessidade de estabelecer uma nova política diante do capital internacional que passava a substituir o capital nacional no processo de industrialização, trazendo tecnologias, financiamento e padrões de competitividade de economias que já tinham produtos tecnologicamente maduros. Segundo Santos, era inevitável, que esse capital internacional submetesse o capital nacional à sua dinâmica, que refletia a força emergente de uma economia mundial baseada num novo tipo de empresa multinacional.

Durante as décadas de 1950 e 1960 o processo de industrialização dos países dependentes ainda se processava por meio da substituição de importações, porém também se produzia novos produtos - inovações financiadas pelo capital internacional.

Em meados da década de 1980, a América Latina estava sofrendo uma ofensiva neoliberal relacionada ao ajuste de suas economias para pagar a dívida externa com taxas de juros elevadas. Isso levou os governos locais a estimularem as exportações como forma de gerar divisas internacionais (moeda estrangeira) para saldar seus compromissos externos. Resultado: criação de um excedente exportador (utilizado para pagamento da divida) pela região, gerando aumento da distribuição de renda negativa e com isso a elevação da marginalização e da pobreza, entre outras mazelas.

Diante disso, com o processo de ajuste estrutural que América Latina teve que passar, os Estados da região sofreram um enfraquecimento no qual simultaneamente repassavam seus recursos para o sistema econômico mundial e criavam uma grande dívida interna com elevadas taxas de juros. Esses processos de ajustes para atender ao sistema econômico mundial, segundo Santos, permanecem sendo a essência da história da região. Os regimes ditatoriais que foram impostos acabaram favorecendo o aprofundamento da dependência, gerando condições extremamente desfavoráveis a uma ação política contestatória.

Assim, a América Latina se configura como uma região de economia dependente. Seu processo de industrialização foi ditado pelas grandes potencias capitalistas da época, através da importação de capitais que possibilitava à região investir em mais infraestrutura para dar suporte a esse processo. Contudo, a infraestrutura e a tecnologia incorporada eram obsoletas, haja vista sua origem ser o 
excedente dos países centrais que já estavam com uma tecnologia mais avançada e especializada. Eles precisavam encontrar um destino para as maquinarias e tecnologia ultrapassadas, configurando um perfeito negócio, no qual as potencias capitalistas disponibilizavam o capital para os países subdesenvolvidos realizarem investimentos no processo de industrialização e também ofereciam as maquinarias e tecnologias (atrasadas) a serem compradas. Logo, a industrialização que se configurava na América Latina era inferior a dos países centrais.

Outra característica histórica da dependência latino-americana, é que seu mercado consumidor esteve voltado para o exterior. Não se tinha a pretensão de formar um mercado interno. A região exportava matéria-prima a preços baixos e importava manufaturados a preços elevados, favorecendo uma indústria especializada em manufaturados nos países centrais e perpetuando a condição de exportador de bens primários para região. Assim, se tinha uma conta que não fechava. Gastava-se mais e ganhava menos. Pode-se acrescentar a isso a tendência à estagnação e baixa nos preços das matérias-primas e elevação no preço das manufaturas. Essa situação é o que Marini (2011) denomina de troca desigual.

Diante desse cenário, o trabalhador ficava ainda mais vulnerável à exploração do capitalismo local, pois para suprir o déficit gerado com a troca desigual, praticava-se a diminuição da remuneração paga, chegando a níveis muito inferiores a dos trabalhadores dos países centrais, impunha-se o aumento da jornada de trabalho, visando aumentar a exportação e com isso a elevação dos lucros. Essas práticas utilizadas para compensar a perda estabelecida pela troca desigual, Marini denomina de superexploração do trabalho, justificando essas práticas devido à ausência de tecnologia que aumentasse a produtividade do trabalho.

Outro conceito que Marini traz para a discussão da economia dependente na América Latina é o de subimperialismo, que é a condição que determinados países periféricos assumem a partir de sua industrialização. A nova condição de suas economias não lhes permite se igualar aos países centrais, mas possibilita estabelecer relações com outras nações que se encontram em condição de inferioridade, se alimentando de alguma forma desta relação em detrimento do país que permaneceu com sua economia como primária. 


\section{EXTRAÇÃO DO MANGANÊS DO AMAPÁ PELA GRANDE EMPRESA MINERADORA}

Num contexto pós-Guerras Mundiais, marcado pela busca da industrialização por países subdesenvolvidos, mudanças na divisão internacional do trabalho e a guerra fria que dividiu o mundo em EUA e URSS, gerou-se muitas crises no mundo, consequentemente nas relações internacionais. Esses elementos se expressaram na questão mineral, tendo algumas minas se esgotado e outras que enfrentavam guerras internas de libertação ou mantinham alianças com o governo da URSS.

Esse cenário acabou promovendo indefinição quanto à estabilidade do abastecimento das indústrias dos EUA e Europa, fato que resultou na busca por novas fontes de reservas minerais por parte dessas economias. Ainda nesse panorama, descobriu-se o manganês no Amapá. Decorrente da busca por novas fontes de minério de ferro na região.

O manganês era um minério estratégico para a economia mundial, essencial na siderurgia, sobretudo para a produção de aço. Os EUA eram o maior produtor e consumidor de aço, tendo consumido, entre 1955 e 1957, em média mais de 2.150 .000 toneladas de manganês. Vale ressaltar que até 1938, a URSS havia sido a principal abastecedora de manganês da economia estadunidense, mas, devido o desenrolar da Segunda Guerra Mundial e posteriormente a uma lei que proibia a exportação para esse país e seus aliados de materiais que pudessem ter fins militares ou paramilitares, a URSS findou o abastecimento. Com isso, países como a Índia, Brasil e Costa do Ouro ganharam maior importância para os EUA.

A partir de 1957, com a imposição de novas condições à exportação pela Índia, aumentando seus preços, incluindo o fato de ser necessário utilizar o Canal de Suez para transportar o minério para os EUA, fez com que o Brasil se tornasse, no fim da década de 1950, o principal exportador para os norte-americanos. Assim, o manganês presente no Território Federal Amapaense, particularmente, teve grande importância estratégica devido a sua localização geográfica muito mais próxima do mercado norte-americano. O minério amapaense saía diretamente no Atlântico, num ponto bem mais próximo dos EUA.

Com a confirmação da presença do deposito de manganês do território federal amapaense, mais especificamente em Serra do Navio e com a constatação de que o minério ali presente era de alto teor e grande volume, incluída a proximidade que 
poderia se ter com o mercado norte-americano, fez com que se verificasse uma grande viabilidade econômica.

Assim, em 4 de dezembro de 1947, por meio de um decreto, o presidente Dutra autorizou o governo do Amapá a assinar um contrato de prospecção com a Icomi. Esse contrato seria redigido pelo CNMM e executado sob a sua supervisão (SILVA, 1988).

[...] a Icomi soube inteligentemente se aproveitar das diferenças entre a corrente desenvolvimentista (nacionalista ou não) e a liberal. Quando se fez necessário, recorreu a um discurso nacionalista, chamando o Estado a apoiar a indústria nacional. Por outro lado, também recorreu ao capital externo e a uma companhia multinacional para garantir a exploração do manganês amapaense - chegando inclusive a dividir com essa companhia o capital da empresa que se instalava no Amapá (MARQUES, 2009).

Segundo Marques (2009), de modo geral, a proposta da Icomi assemelhava-se àquela apresentada em 1945 pela Hanna Company (empresa envolvida na exploração sem sucesso de minério de ferro na região) que incluía construção de obras de infraestrutura, estudo da viabilidade econômica do empreendimento, construção de uma estrada de ferro e porto no delta do Amazonas, desde que as jazidas alcançassem pelo menos 10 milhões de toneladas de alto teor, pagamento ao Território Federal Amapaense de $4 \%$ do valor de venda do minério, concessão de 2.500 ha de terra para pesquisa e lavra, cinquenta anos para arrendamento das jazidas a partir do momento em que a Icomi tomasse a decisão de levar à frente a exploração do minério e pagamento de adicional de $1 \%$ ao Território Federal do Amapá ou obrigatoriedade de a empresa investir no Amapá 20\% dos seus lucros líquidos.

Contribuíram para a instalação da Icomi no Amapá o cenário internacional, as polêmicas entre nacionalistas e desenvolvimentistas e o consumo de manganês pela indústria brasileira que era ainda muito reduzida, ficando, em 1958, em pouco mais de cinquenta mil toneladas anuais, o que era abastecido pela jazida presente em Minas Gerais.

A Icomi iniciou a prospecção do minério em Serra do Navio, no ano seguinte em que assinou o contrato com o governo do território federal amapaense. Nesse primeiro momento o objetivo era o de encontrar pelo menos 10 milhões de toneladas de minério para que o empreendimento tivesse condições de competir no mercado internacional de manganês. 
Para que o empreendimento se desenvolvesse era necessário um alto investimento por parte da Icomi, que tinha uma limitação financeira, haja vista que o mesmo passava por etapas de pesquisa, prospecção, instalações para o beneficiamento do minério, construção de ferrovia, porto, alojamentos, entre outras. De inicio, tentou-se obter esse capital para investimento através de acordos com empresas brasileiras para exploração do manganês, porém devido a obstáculos principalmente no âmbito da comunicação, transporte e energia.

O grau de desenvolvimento da acumulação de capital do empresariado brasileiro, que dispunha de pouco capital para um investimento bastante distante do centro dinâmico do processo de industrialização brasileiro - no caso, o Sudeste também foi um dos motivos dessa tentativa não ter tido sucesso. Assim, com as dificuldades financeiras da Icomi, a falta de dinheiro do governo brasileiro para financiar os vultosos investimentos da exploração do manganês de Serra do Navio e, a não concretização da associação com empresários brasileiros, a alternativa encontrada foi recorrer ao exterior.

Para efetivar a participação de uma empresa estrangeira no empreendimento, a Icomi fez dois movimentos: um interno, reestruturando seu estatuto, e outro externo, revisando o contrato firmado entre ela e o governo do Amapá em 1947. Quanto às mudanças internas, podemos destacar a redefinição do seu status legal e financeiro para acomodar a Bethlehem Steel na exploração do manganês (MARQUES, 2009).

A Bethlehem Steel, empresa norte-americana, em 9 de junho de 1949, assinou o acordo com a Icomi. A partir dessa nova composição da empresa, cria-se a Companhia Auxiliar de Empresas de Mineração (Caemi), em 1950, visando comportar os empreendimentos do grupo Antunes (Icomi) e, ao mesmo tempo, permitir formalmente a entrada da empresa norte-americana no capital da Icomi.

Segundo Marques (2009), também como parte das mudanças necessárias para a participação estrangeira, foram introduzidas novas mudanças no estatuto da Icomi, criando uma nova categoria de ações, denominada de ao portador.

[as ações] poderiam pertencer a investidores individuais ou a instituições anônimas, num limite de até $49 \%$ do capital social da empresa. Os donos das ações ao portador não tinham direito de voto e as demais ações nominativas só poderiam pertencer a brasileiros ou a uma sociedade organizada no país e constituída por sócios brasileiros e que deveriam sempre exceder os $51 \%$ do capital social (DRUMMOND e PEREIRA, 2007).

Assim, as ações normativas majoritárias da Icomi ficaram com o grupo Caemi e as ações ao portador foram passadas a empresa norte-americana. Formalizando-se a associação entre ambas dentro da legislação mineral brasileira em vigor. Essa legislação exigia que a empresa que explorasse o manganês da Serra do Navio fosse de 
propriedade de brasileiros natos e que eventuais participações de acionistas estrangeiros fossem minoritárias (MARQUES, 2009).

O plano da companhia norte-americana era a exploração do minério para abastecer suas siderurgias nos EUA, que era seu principal mercado consumidor. Instalar uma siderurgia no Amapá, nunca foi plano da Behthlehem Steel, pelo volume financeiro que o investimento necessitaria.

Para começar a prospecção, segundo o contrato firmado com o Território Federal Amapaense, era necessário que existisse 10.000.000 de toneladas de minério de manganês para justificar os gastos e investimentos que dependeriam sua extração. Em 1951, a Icomi e a Bethlehem Steel apresentam ao governo do Território o relatório final de prospecção, no qual apontava para a existência de 10.000.000 de toneladas de minério de manganês de alto teor.

Assim, com o respaldo do governo do território federal amapaense e o resultado da pesquisa acerca do volume de minério existente, segundo Marques (2009), a empresa resolveu buscar financiamento externo para a implantação do empreendimento. Deduzindo-se que a entrada da Bethlehem Steel na composição acionária da Icomi também foi estratégica devido a necessidade de captação de um empréstimo externo. Já que com companhia estadunidense como co-proprietária, ficava mais fácil obtê-lo.

O empréstimo foi concedido pelo Eximbank e para que fosse concretizado precisava-se da garantia de que existia mercado para o produto. Diante disso, a Icomi assinou, então, o acordo de garantia de mercado com o Defense Materials Procurement Agency (DMPA). Pelo acordo, o DMPA garantia a compra das primeiras 5,5 milhões de toneladas produzidas de manganês (ao preço de US\$ 0,65 CIF-Baltimore a tonelada), das quais $30 \%$ seriam comercializadas com um abatimento de $10 \%$ em relação ao preço médio do mercado. A Icomi ficava obrigada a vender aos EUA 70\% do manganês produzido e exportado; os $30 \%$ restantes poderiam ser vendidos a outros países, desde que cumpridas algumas exigências relacionadas ao pagamento do empréstimo (CUNHA, 1962; SILVA, 1988 apud MARQUES, 2009).

Segundo Marques (2009), para não causar nenhum tipo de atraso ou dificuldade política, as exigências feitas pelo Eximbank foram validadas pelas mais altas hierarquias do governo federal brasileiro, sem passar pelo Congresso. $\mathrm{O}$ empréstimo foi aplicado às obras principais do projeto de aproveitamento das jazidas de manganês, sendo elas: a construção da estrada de ferro, do porto de embarque, da base de extração e beneficiamento e das duas vilas residenciais. 
Segundo Marques (2009), a produção da Icomi representou mais que uma inovação produtiva no Amapá, foi também um forte incremento produtivo na Região Norte, haja vista que anteriormente os índices de produção eram baixos e sua relação com o exterior inexpressiva. A tabela a seguir demonstra a mudança no âmbito da exportação na região, com forte destaque para o manganês.

\begin{tabular}{|c|c|c|}
\hline \multicolumn{3}{|c|}{$\begin{array}{c}\text { Tabela: Exportação da região Norte para o exterior, } \\
1958 \text { (Valores FOB a preços de 1974) }\end{array}$} \\
\hline Produtos & US\$ mil & Percentual \\
\hline Manganês & $45.200,3$ & $62,1 \%$ \\
\hline Castanha-do-Pará & $20.163,1$ & $27,7 \%$ \\
\hline Couros e peles & $2.120,6$ & $2,9 \%$ \\
\hline Borracha e resinas & $2.061,9$ & $2,8 \%$ \\
\hline Madeira em tora ou serrada & 761,3 & $1,1 \%$ \\
\hline Óleo de pau rosa & 679,7 & $0,9 \%$ \\
\hline Pimenta-do-reino & 577,5 & $0,8 \%$ \\
\hline Produtos da pesca & 46,5 & $0,1 \%$ \\
\hline Diversos & $1.233,3$ & $1,7 \%$ \\
\hline Total & $72.844,2$ & $100,0 \%$ \\
\hline
\end{tabular}

A produção do manganês amapaense pela Icomi sofreu muitas oscilações, caracterizadas basicamente pelas disputas no mercado internacional. Em relação à quantidade exportada o volume foi crescente de 1957 até 1963, caindo de 1964 até 1967 (MARQUES, 2009).

O manganês amapaense destacou-se na pauta de exportações brasileiras, se apresentando, em 1957, como o $7^{\circ}$ maior produto no valor das exportações nacionais. Deste ano até 1961 as vendas externas da Icomi representaram em média $88 \%$ das exportações brasileiras de manganês, se mantendo em $84 \%$ no intervalo entre 1967 e 1971 . Esta produção foi muito significativa para a economia amapaense, mas também para a própria região Norte. No tocante ao Amapá a expressividade desta mineração foi maior devido a sua frágil e reduzida economia, diminuta e empobrecida população e insipiente organização estatal e da sociedade local (MARQUES, 2009).

No início da década de 1960 o mercado mundial do manganês passou por importantes transformações, que influenciaram na produção deste mineral no Amapá. Com o início das operações da mina Comilog no Gabão, gerou-se um movimento de oferta ampliada do manganês no mercado internacional que se manteve na década de 1970. Contudo, com redução do consumo deste minério em decorrência dos avanços tecnológicos na siderurgia, esse movimento foi afetado. As inovações técnicas possibilitaram reduzir o volume de manganês necessário para cada tonelada de aço produzido. 
Segundo Marques (2009), diante desse cenário, a Icomi, para compensar a queda dos preços no mercado internacional, impulsionou suas vendas, ou seja, procurou vender mais para manter uma receita elevada. $\mathrm{O}$ aumento das exportações implicava a expansão das quantidades produzidas, ainda que para isso tivesse que adotar um turno extra de trabalho. A produção não poderia ser interrompida.

Como reflexo das mudanças no mercado mundial, a Icomi passou por mudanças significativas na sua organização industrial de produção, introduzindo novas tecnologias para o aproveitamento do minério, resultando na construção da usina de concentrado de miúdo e fino na Serra do Navio e da usina de pelotização no porto de Santana. Objetivava-se aproveitar o minério até então descartado, particularmente, aquele de baixo teor.

A partir da conclusão do pagamento do empréstimo tomado junto ao Eximbank e de outros fatores já citados, esta procura diminuiu e a empresa deslocou significativamente suas vendas para a Europa. A diversificação do destino de venda passou, assim, a incorporar inclusive o mercado interno brasileiro como destino do manganês produzido pela Icomi no Amapá. A partir de 1971 o Brasil se tornou permanentemente um dos destinos do manganês amapaense, mas ainda em proporções reduzidas.

A dinâmica de queda das importações do minério amapaense pelos Estados Unidos a partir da década de 1970, e principalmente na seguinte, foi um indicador da perda de interesse da Bethlehem Steel no empreendimento da qual ela fez parte no Amapá. Em 1988, a companhia multinacional vendeu as ações de que era proprietária na Icomi.

Diante desse cenário, o grupo Caemi lançou mão de algumas ações com a intenção de responder à perda de produtividade da Icomi, com a proximidade nos anos 1980 da exaustão das minas de manganês e a redução do seu volume exportado e das receitas destas vendas. A diversificação realizada pela empresa (construção das usinas de pelotização e de sinterização) decorria das exigências do mercado mundial de manganês.

Nos anos 1990 confirmou-se a exaustão das minas e a decadência da produção na Serra do Navio, levando a uma perda de interesse por parte da empresa no empreendimento lá localizado, uma vez que só fazia sentido continuar a produção se a perspectiva de lucro se mostrasse viável. Assim, paulatinamente, a Icomi foi desmontando sua estrutura de produção e em 20 de novembro de 1997, a companhia 
enviou ao Ministério das Minas e Energia e ao Departamento Nacional de Produção Mineral (DNPM) solicitação oficial de autorização para encerrar as atividades mineradoras. Cinco anos antes de completar o prazo estipulado no contrato, a empresa oficialmente encerrou suas atividades de extração do manganês no Amapá.

\section{A PERMANÊNCIA DA ECONOMIA PRIMÁRIO-EXPORTADORA}

Pode-se dizer que a formação de uma economia primário-exportadora se iniciou desde o período de colonização portuguesa na Amazônia brasileira. Colonização essa, sustentada num modelo extrativista, no qual se tinha intensa apropriação da natureza e baixa agregação de valor.

Final do século XIX, a região amazônica começa a viver a economia da borracha. Os olhares direcionam-se para Amazônia, agora devido à necessidade da indústria internacional por látex, sendo a região potencial fornecedora. A economia da borracha teve o aviamento como modelo de organização da produção. Ela era controlada pelo capital comercial. Reforçava-se assim, uma economia sustentada no extrativismo tradicional.

No início do século XX, a economia amazônica entra em crise devido à queda do preço do látex no marcado internacional e só começa a se recuperar de forma mais efetiva em meados das décadas de 1950 e 1960, principalmente depois do estabelecimento da ditatura empresarial-militar (1964). De acordo com Marques (2012), a ditadura brasileira impulsionou na Amazônia projetos para exploração mineral em escala industrial, direcionados para o exterior.

A ditadura empresarial-militar configurou várias mudanças na região amazônica. Essas se deram por meio da implantação de grandes empreendimentos: projeto Jari, criação de órgãos como a Suframa e a SUDAM (que substituiu a SPVEA), fundação do BASA (Banco da Amazônia) e política de ampliação de incentivos fiscais. No âmbito nacional, o Estatuto da Terra e o novo Código de Mineração também contribuíram para essas mudanças. Todos esses elementos colaboraram para que na segunda metade da década de 1970 a região inserida no processo de acumulação de capital no Brasil e na Divisão Internacional do Trabalho exercesse função de exportadora de produtos minerais (MARQUES, 2012). 
Uma expressão dessa nova função foi o Polamazônia (1974) que visava “ocupar os espaços vazios e a utilização dos eixos viários articulando-se aos projetos de desenvolvimento setorial nas áreas preferenciais" (SUDAM apud MARQUES, 2012, p. 46). O polo de Carajás concentrou mais investimentos devido às reservas de ferro e posteriormente, ganhou vida própria transformando-se no Programa Grande Carajás. Essa concentração de recursos justificava pelos "interesses naturais" na Amazônia, particularmente à busca de divisas internacionais por meio da exploração de seus recursos naturais (MARQUES, 2012, p.37).

Assim, o processo de ocupação se deu através dos grandes empreendimentos governamentais e privados, sendo a região inserida na estratégia econômica imperialista por meio dos grandes projetos energético- minerais. Vários foram instalados na Amazônia oriental, exemplos são: Ferro-Carajás e os de alumínio como o Trombetas, Albrás/Alunorte e Alumar (MARQUES, 2012).

Os projetos em torno da grande mineração envolviam interesses e capitais que extrapolavam em muito a capacidade de intervenção da burguesia regional amazônica e tinham como objetivo pilhar os recursos naturais. Em relação à economia regional, com os grandes projetos ocorreu uma reconfiguração produtiva e relação com o exterior, mas confirmando sua condição de região semicolonial (MARQUES, 2012, p. 39).

Segundo Marques (2012), mesmo diante de toda diversidade mineral existente na região e no Pará, sua pauta de exportação sustenta-se basicamente em poucos produtos, básicos, principalmente minerais e com predominância do ferro.

É uma produção sem grande beneficiamento, e, portanto, de baixa agregação de valor. É riqueza bruta comercializada a preços baixos com o exterior - particularmente se compararmos aos preços dos produtos industrializados. Isso fica evidente na tabela a seguir, onde se conclui que a produção industrializada (manufaturada) é pequena quando comparada aos produtos básicos. 


\begin{tabular}{c|c|c|c}
\multicolumn{4}{c}{ EXPORTAÇÃO PARAENSE POR FATOR AGREGADO } \\
\hline Ano & TOTAL & Básicos & Manufaturados \\
& US\$ FOB & US\$ FOB & US\$ FOB (B) \\
\hline 2000 & 2.441 .275 .870 & 1.086 .495 .619 & 350.587 .025 \\
\hline 2001 & 2.289 .087 .011 & 1.108 .119 .025 & 313.406 .474 \\
\hline 2002 & 2.266 .867 .807 & 1.077 .337 .148 & 300.798 .660 \\
\hline 2003 & 2.677 .553 .496 & 1.210 .213 .763 & 516.165 .284 \\
\hline 2004 & 3.804 .905 .385 & 1.788 .488 .670 & 698.581 .720 \\
\hline 2005 & 4.807 .893 .461 & 2.439 .036 .688 & 811.135 .870 \\
\hline 2006 & 6.707 .888 .191 & 3.204 .354 .142 & 1.388 .566 .925 \\
\hline 2007 & 7.925 .093 .138 & 3.949 .680 .182 & 1.705 .122 .243 \\
\hline 2008 & 10.680 .513 .954 & 6.289 .445 .265 & 1.898 .642 .283 \\
\hline 2009 & 8.345 .255 .133 & 5.456 .857 .880 & 1.523 .052 .213 \\
\hline 2010 & 12.835 .420 .476 & 9.368 .252 .333 & 1.735 .117 .147 \\
\hline 2011 & 18.336 .604 .195 & 14.334 .178 .342 & 1.872 .881 .470 \\
\hline 2012 & 14.795 .448 .748 & 11.462 .027 .363 & 1.599 .236 .006 \\
\hline 2013 & 15.852 .091 .025 & 13.299 .135 .439 & 1.335 .390 .178 \\
\hline dados dos semimanufaturados e de operações especiais.
\end{tabular}

Em suma, o interesse das mineradoras é a extração mineral simples, sem beneficiamento. De alguma forma isso acontece até mesmo no caso da produção do alumínio primário, pois essa fase de beneficiamento ocorre na região pelo fato de ser intensiva em consumo de energia, além de forte produtora de rejeitos. A Usina Hidrelétrica de Tucuruí foi construída para fornecer energia subsidiada para os dois complexos de alumínio no Pará e no Maranhão.

Essa é a função da Amazônia na atual DIT imposta pela acumulação de capital na lógica da globalização do saque, ditada pelas multinacionais, incluída a Vale. A possibilidade de alguma transformação mineral depende da oferta pública de energia barata; por isso a pressão pela construção de hidrelétricas pelo governo" (MARQUES, 2012, p. 42).

No Pará, a maior parte do que é exportado advém da extração mineral, o que expressa a importância da indústria mineral para o estado. Na região Norte não é diferente. Sua balança comercial é hegemonizada por minérios e produtos do agronegócio - veja a tabela seguinte. 


\begin{tabular}{|c|c|c|}
\hline \multicolumn{3}{|c|}{$\begin{array}{l}\text { PAUTA DA BALANÇA COMERCIAL DA REGIÃO NORTE - } 20 \\
\text { PRINCIPAIS PRODUTOS EXPORTADORES }\end{array}$} \\
\hline TOTAL GERAL & 3.206 .860 .584 & 100,00 \\
\hline $\begin{array}{l}\text { MINERIOS DE FERRO NAO AGLOMERADOS E SEUS } \\
\text { CONCENTRADOS }\end{array}$ & 3.972 .062 .771 & 30,08 \\
\hline OUTROS MINERIOS DE COBRE E SEUS CONCENTRADOS & 1.642.191.791 & 12,43 \\
\hline ALUMINA CALCINADA & 1.414.103.892 & 10,71 \\
\hline SOJA, MESMO TRITURADA, EXCETO PARA SEMEADURA & 1.235 .748 .478 & 9,36 \\
\hline CARNES DESOSSADAS DE BOVINO, CONGELADAS & 804.872 .780 & 6,09 \\
\hline ALUMINIO NAO LIGADO EM FORMA BRUTA & 540.699 .915 & 4,09 \\
\hline OUTRAS PREPARACOES PARA ELABORACAO DE BEBIDAS & 274.959 .348 & 2,08 \\
\hline FERRONIQUEL & 269.113.609 & 2,04 \\
\hline BAUXITA NAO CALCINADA (MINERIO DE ALUMINIO) & 259.543 .728 & 1,97 \\
\hline PIMENTA "PIPER", SECA & 227.639 .182 & 1,72 \\
\hline CAULIM & 191.116.756 & 1,45 \\
\hline OUTRAS MADEIRAS PERF. ETC., NÃO CONIFERAS & 188.908 .476 & 1,43 \\
\hline OURO EM BARRAS, FIOS E PERFIS DE SECAO MACICA & 186.362 .589 & 1,41 \\
\hline OUTROS BOVINOS VIVOS & 120.888 .786 & 0,92 \\
\hline MILHO EM GRAO, EXCETO PARA SEMEADURA & 113.359 .327 & 0,86 \\
\hline $\begin{array}{l}\text { MOTOCICLETAS C/MOTOR PISTAO } \\
\text { ALTERNAT.125CM3<CIL<=250CM3 }\end{array}$ & 106.538 .544 & 0,81 \\
\hline OUTROS MINERIOS DE MANGANES & 101.004 .395 & 0,76 \\
\hline OUTROS SILICIOS & 93.561 .281 & 0,71 \\
\hline HIDROXIDO DE ALUMINIO & 79.195 .706 & 0,60 \\
\hline OLEOS DE DENDE, EM BRUTO & 77.670 .234 & 0,59 \\
\hline
\end{tabular}

Fonte: MDIC - Secretaria de Comércio Exterior

Vale salientar que o minério que é extraído da região gera mais riquezas e emprego nos países para onde se exporta do que para a região. De todo o volume de riqueza produzida pela extração mineral, parte importante fosse revestida para desenvolvimento da região no âmbito social, muito dos danos ambientais e sociais deixados por esses empreendimentos seriam minimizados. Porém, a produção (mineral) está principalmente voltada para geração de lucro e interesses das multinacionais monopolistas.

Corremos o risco de, em alguma medida, reproduzir muitos elementos negativos do caso do Amapá.

Ainda não conseguimos quebrar o padrão de dependência historicamente imposto à Amazônia. Isso tem se reforçado por todas as transformações que a região sofreu e sofre, fazendo com que permaneça como economia primário-exportadora e por conta disso dependente. 


\section{CONSIDERAÇÕES FINAIS}

A extração de manganês no Amapá foi uma experiência de ciclo completo da mineração e por isso deve ser tomada como referência para analisar a grande produção energéticomineral na Amazônia brasileira da atualidade. Descoberto em 1945, teve sua exportação iniciada em 1957 e rapidamente esgotou o minério de alto teor. Quando a mineradora se retirou do estado, restou um rastro de degradação ambiental e social. Serra do Navio, até então uma cidade modelo, transformou-se numa cidade abandonada e sem conservação.

Assim, a experiência ICOMI-Bethlehem Steel no Amapá não conduziu a um processo sólido e duradouro de desenvolvimento socioespacial. Enquanto a mineradora estava explorando a mina, havia dinamização econômica e melhoria das condições de vida das pessoas vinculadas diretamente à mineradora, mas o restante da população ficou alheia a estes benefícios. Nem empresa, nem governo buscaram sedimentar processos duradouros de desenvolvimento que extrapolassem a extração do manganês em si.

Ao final da exploração ocorreu o retrocesso socioespacial, apontando para a compreensão de que esta produção pouco contribuiu para aumentar o grau de autonomia do Estado, ou seja, de desenvolvimento.

Atualmente, a região amazônica, com o Pará em destaque, tem se configurado como uma das grandes produtoras de minério do mundo. Mas permanece concentrada na extração e, quando muito, num beneficiamento primário básico, reforçando o caráter primário-exportador da mesma.

O estudo da grande mineração da Amazônia deve ter como referência o desempenho dos indicadores sociais, de modo a se constatar ou não processos positivos de desenvolvimento socioespacial. Ainda que no presente artigo não tenhamos abordados estes indicadores, eles devem ser permanentemente tomados como referência. A extração mineral que não conduza a processos de desenvolvimento gera tensões e intensificação das contradições sociais e ambientais.

A teoria da dependência, em diálogo com a geografia, pode nos auxiliar neste caminhar, que deve ter o objetivo de colocar as riquezas naturais da região na condição de propulsora de processo de autonomia, ou seja, de desenvolvimento socioespacial. 


\section{REFERÊNCIAS BIBLIOGRÁFICAS}

ARRIGHI, Giovanni e SILVER, Beverly J. Caos e governabilidade no moderno sistema mundial. Rio de Janeiro: Contraponto/Editora da UFRJ, 2001.

CHESNAIS, François. A Mundialização do capital. São Paulo: Xamã, 1996.

DRUMMOND, José A.; PEREIRA, Mariângela. O Amapá nos tempos do manganês: um estudo sobre o desenvolvimento de um estado amazônico - 1943-200. Rio de Janeiro: Garamond, 2007.

GOLDENSTEIN, L. Repensando a Dependência. 1994. 135 f. Tese (Doutorado em Economia) - Instituto de Economia, Universidade Estadual de Campinas, Campinas. 1994.

HARDT, M, NEGRI, A. Império. Rio de Janeiro: Record, 2001.

HOBSBAWM, Eric. Era dos extremos. São Paulo: Companhia das Letras, 2000.

MARQUES, Gilberto. Amazônia: uma moderna colônia energético-mineral? Distrito Federal: ano XXI, nº 49, janeiro de 2012.

MARQUES, Indira. Território Federal e mineração de manganês: gênese do Estado do Amapá. Rio de Janeiro: UFRJ, 2009 (Tese de Doutorado).

LÊNIN, V. I. Imperialismo, fase superior do capitalismo. São Paulo: Global, 1987.

LOUREIRO, Violeta R. Amazônia, Estado, homem, natureza. Belém: Cejup, 2004.

MARINI, Ruy M. Dialética da dependência, 1973. In: TRASPADINI, Roberta; STÉDILE, João P. Ruy Mauro Marini - vida e obra. São Paulo: Expressão Popular, 2011.

DOS SANTOS, Theotonio. Teoria da Dependência: Balanços e perspectivas. Florianópolis: Editora Insular, 2015.

PETRAS, James. Império e políticas revolucionárias na América Latina. São Paulo: Xamã, 2002.

WALLERSTEIN, Immanuel. Após o Liberalismo. Em busca da reconstrução do mundo. Petrópolis: Editora Vozes, 1995.

. World-System Analysis. London: Duke University Press, 2004.

Recebido para publicação em fevereiro de 2016.

Aceito para publicação em abril de 2016. 